\title{
The Effect of Zinc Therapy on Lysosomal Inclusion Bodies in Intestinal Epithelial Cells in Acrodermatitis Enteropathica
}

\author{
JOHN GWYN JONES, MARGARET E. ELMES, ${ }^{(19)}$ PETER J. AGGETT, AND JOHN T. HARRIES \\ Department of Pathology, University Hospital of Wales, Heath Park, Cardiff, [J.G.J., M.E.E.] University of \\ Aberdeen, Centre for Study of Metabolism of Trace Elements, Marischal College, Aberdeen, [P.J.A.] Institute of
} Child Health, 30 Guilford Street, London, Great Britain [J.T.H.]

\section{Summary}

Two patients with acrodermatitis enteropathica had abnormal lysosomal inclusion bodies in the intestinal epithelial cells while in relapse but fewer smaller ones after zinc therapy. The third patient with acrodermatitis enteropathica in remission on zinc therapy had no inclusion bodies. The smaller inclusion bodies were similar to those found in coeliac disease.

\section{Abbreviation}

\section{AE, acrodermatitis enteropathica}

Lysosomal inclusion bodies have been described in the apical cytoplasm of small intestinal epithelial cells in $\beta$ lipoprotein deficiency (6), coeliac disease (14), tropical sprue (12), infantile malnutrition (5), Crohn's disease (15), and after aspirin ingestion (9). It has been suggested that these inclusion bodies are autophagosomes, bacteria or dead epithelial cells ingested by their neighbours.

Previous electron microscopic studies of the mucosa in acrodermatitis enteropathica (AE) have demonstrated cytoplasmic vesicles and dilated intercellular spaces in the epithelial cells (13), abnormal Paneth cells (11) and both abnormal Paneth cells and multivesicular bodies in the enterocyte $(3,4)$.

This paper describes very large lysosomal inclusion bodies found in two patients with AE and the effect of zinc therapy on these bodies.

\section{MATERIALS AND METHODS}

Three patients with AE were studied. Biopsies were taken under fluoroscopic control just distal to the Ligament of Trietz using a two-port biopsy capsule. One biopsy was used for an investigation of the $\left[{ }^{65} \mathrm{Zn}\right]$ uptake by the mucosa, and this work is reported elsewhere (1). The tissue:medium concentration ratios, which are a measure of the mucosal uptake of zinc, are included in Table 1, which gives details of the patients and therapy. These biopsies were compared with a total of 52 jejunal biopsies taken for diagnostic purposes (44 children and eight adults) with normal histology and ultrastructure and a total of 15 jejunal biopsies (eight children and seven adults) in which a diagnosis of coeliac disease was made on clinical history and histologic and ultrastructural findings. All biopsies were fixed in $2.5 \%$ glutaraldehyde in phosphate buffer $\mathrm{pH} 7.4$, post-fixed in $1 \% \mathrm{OsO}_{4}$, dehydrated and embedded in epon or araldite. Semithin and ultrathin sections were cut using an LKB ultramicrotome and glass knives. The semithin sections were mounted on glass slides, stained with toluidine blue and observed in a light microscope. The ultrathin sections were transferred to copper/nickel grids, double stained with a saturated solution of uranyl acetate in 50\% ethanol and Reynold's lead citrate and observed in a Philips 300 transmission electron microscope.

\section{RESULTS}

All the patients described as histologically normal at the light microscope level had normal ultrastructure (16). In the AE patients

Table 1. Clinical and biochemical details of the three patients with acrodermatitis enteropathica studied

\begin{tabular}{|c|c|c|c|c|c|c|}
\hline Patient & Age & Therapy $^{1}\left(\mathrm{mg} \mathrm{ZnSO}_{4}\right)$ & $\begin{array}{l}\text { Plasma zinc }{ }^{2} \\
(\mu \text { mole/liter })\end{array}$ & $\begin{array}{c}\text { Plasma }^{2} \text { alkaline } \\
\text { phosphatase (i.u./ } \\
\text { liter) }\end{array}$ & T:M ratio ${ }^{3}$ & Clinical features \\
\hline \multirow[t]{2}{*}{$1 \mathrm{~F}$} & $9 \mathrm{y} 3 \mathrm{mo}$ & None & 3.7 & 43 & 1.55 & $\begin{array}{l}\text { Depressed mood; anorexic; oral, } \\
\text { facial, and acral dermatitis; hy- } \\
\text { perkeratosis on thighs }\end{array}$ \\
\hline & $9 \mathrm{y} 6 \mathrm{mo}$ & $\begin{array}{l}220 \mathrm{mg} \\
\text { (three times a day) }\end{array}$ & 14.9 & 140 & 1.67 & Asymptomatic, normal skin \\
\hline $2 \mathrm{~F}$ & $5 y 3 \mathrm{mo}$ & None & 8.6 & 101 & 1.81 & $\begin{array}{l}\text { Depressed; cheilitis; nasolabial } \\
\text { and retroauricular eczematous } \\
\text { plaques }\end{array}$ \\
\hline $3 \mathrm{M}$ & 4y $1 \mathrm{mo}$ & $\begin{array}{l}100 \mathrm{mg} \\
\text { (twice a day) }\end{array}$ & 15.8 & 132 & 1.96 & Asymptomatic \\
\hline
\end{tabular}

${ }^{1} 220 \mathrm{mg} \mathrm{ZnSO}_{4}$ contains $50 \mathrm{mg}(0.76 \mathrm{mmole})$ elemental zinc.

${ }^{2}$ Laboratory reference ranges: plasma zinc, $11-24 \mu$ mole/liter $(72-157 \mu \mathrm{g} / 100 \mathrm{ml})$. Age and sex related alkaline phosphate: patient 1 , 78-185 i.u./liter and patients 2 and 3, 71-177 i.u./liter.

${ }^{3}$ Control values $(n=11) 4.3-11.0($ mean \pm S.E. $7.5 \pm 0.8)$. 
abnormal inclusion bodies and secretory granules similar to those described previously (11) were present in some Paneth cells. The enterocytes of Patient 3 (on zinc therapy) had normal ultrastructure; however, very large abnormal lysosomal inclusion bodies were found in the apical cytoplasm of some enterocytes in AE patients 1 and 2. These inclusion bodies were not found on all villi and when present could be found in any region of a villus. On some villi, groups of inclusion body-containing enterocytes were present and inclusion body-containing enterocytes were occasionally found along the whole length of a villus.

In the first biopsy of Patient 1 (AE in relapse), the inclusion bodies were generally round in shape, contained floccular electron dense material and were 1.5-3.5 $\mu \mathrm{m}$ in diameter (Fig. 1). Other smaller heteromorphic inclusion bodies were also present and these were found together with the larger bodies in the same enterocyte but generally in a more apical position in the cytoplasm. In the second biopsy of Patient 1 (AE in remission), the inclusion bodies were different from those described above. They were generally round in shape and varied from $0.5-2.0 \mu \mathrm{m}$ in diameter. Each inclusion body contained numerous pleomorphic electron dense granules, which were surrounded by a halo of electronlucent material and the background substance was very electron dense (Fig. 2). The inclusion body granules were very similar in ultrastructure to the goblet cell granules found in this biopsy (Fig. 3).

In Patient 2, lysosomal inclusion bodies were only found in the second biopsy (AE in relapse) and were smaller and fewer in number than those found in Patient 1 . The inclusion bodies were round in shape and contained remnants of degenerating cellular organelles such as mitochondria (Fig. 4). The inclusion bodies were found together with smaller electron dense bodies similar to the lysosomes found in normal biopsies. In this biopsy the majority of enterocytes contained numerous small electron dense lysosomes.

Pleomorphic lysosomal inclusion bodies were seen on numerous occasions in the villous enterocytes of some patients with coeliac disease (children and adults). The inclusion bodies varied from $0.5-1.8 \mu \mathrm{m}$ and contained electron dense material together with structures resembling cellular organelles (Fig. 5). Some of the inclusion bodies were very similar in morphology to those seen in $\mathrm{AE}$ and inclusion bodies containing structures resembling those found in degenerating goblet cells were often found (Fig. 6).

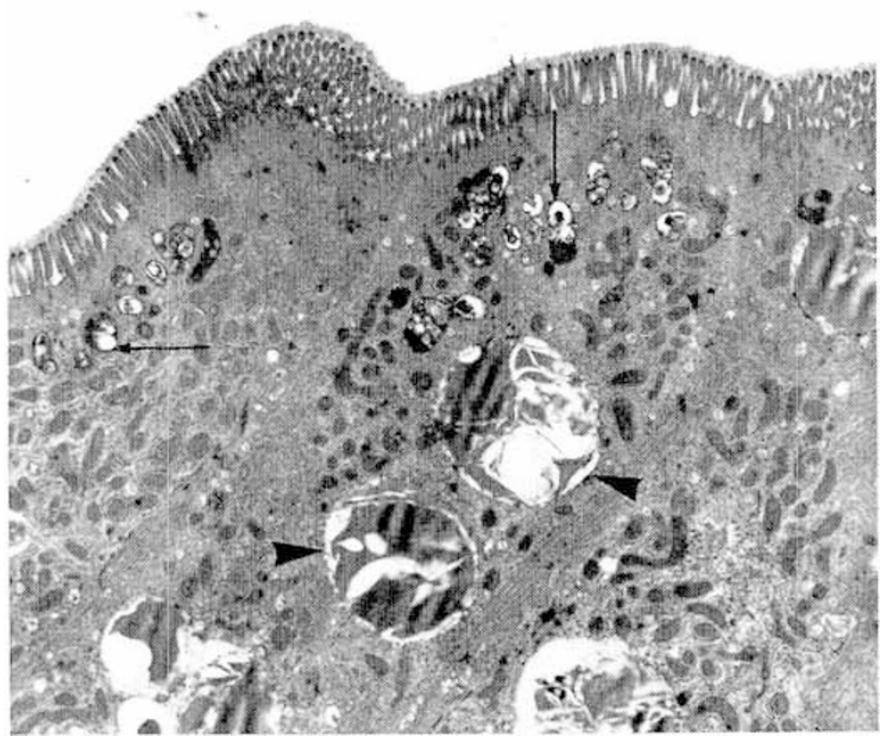

Fig. 1. Villous enterocytes containing large inclusion bodies with a floccular electron dense composition (arrowheads) and small heteromorphic inclusion bodies (arrows). A.E. Patient 1 (in relapse). Jejunum $\times 8800$.
Similar inclusion bodies to those seen in AE or coeliac disease were never seen in normal biopsies.

\section{DISCUSSION}

Lysosomal inclusion bodies do occur in small numbers in the intestinal epithelial cells of normal subjects but large numbers are only found in disease states. This is confirmed by our observation that one patient with $\mathrm{AE}$ had no inclusion bodies while in remission after zinc therapy, but several small ones were observed in relapse. The other patient with $\mathrm{AE}$ in relapse with a very low plasma zinc had many large inclusion bodies but fewer smaller ones after the commencement of zinc therapy. The third $\mathrm{AE}$ patient who was in remission on zinc therapy had no inclusion bodies. These inclusion bodies are not specific to $\mathrm{AE}$ as we have observed them in coeliac disease, confirming other workers' observations (14).

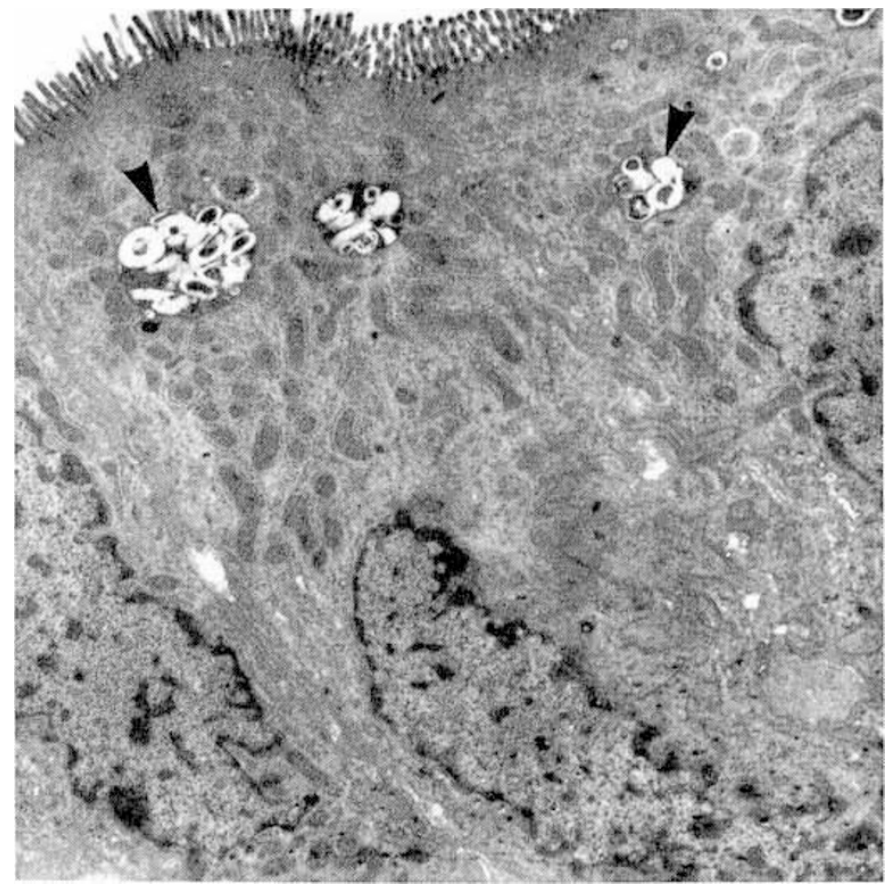

Fig. 2. Villous enterocytes with large granule containing inclusion bodies (arrowheads). Note electron density of granules and their surrounding electron lucent halos. A.E. Patient 1 (in remission). Jejunum $\times 8800$.

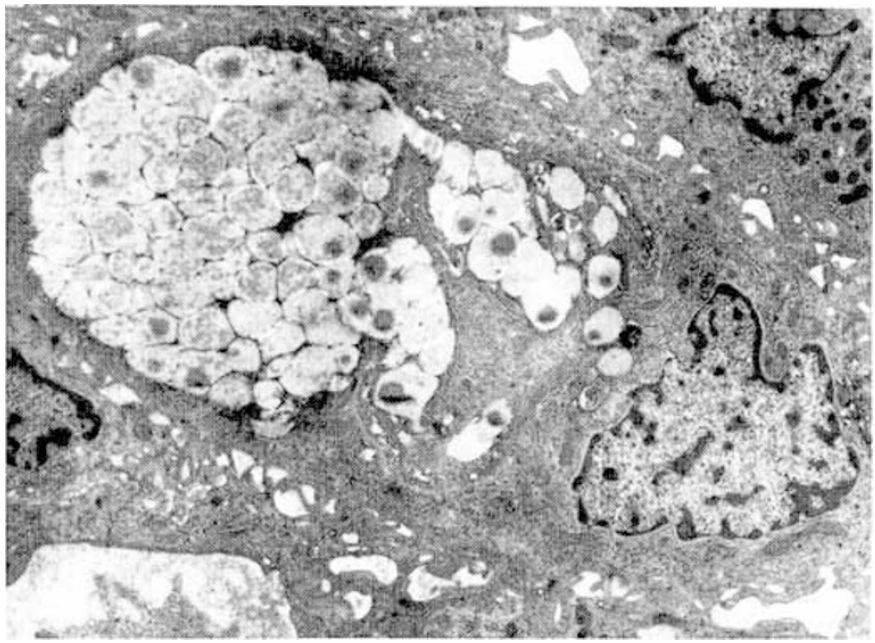

Fig. 3. Goblet cell with secretory granules of similar composition to those seen in the inclusion bodies of Figure 2. A.E. Patient 1 (in remission). Jejunum $\times 8800$. 


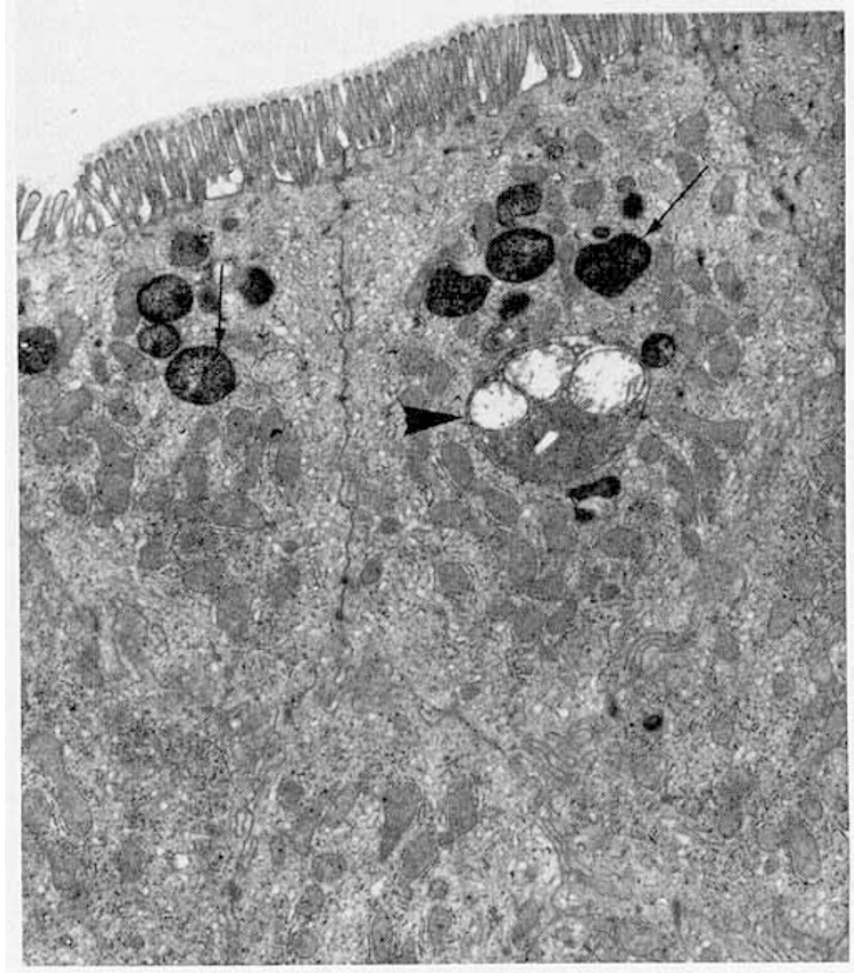

Fig. 4. Villous enterocyte with a large inclusion body containing remnants of mitochondria (arrowhead). Numerous lysosomes (arrows) are also present. A.E. Patient 2 (in relapse). Jejunum $\times 8800$.

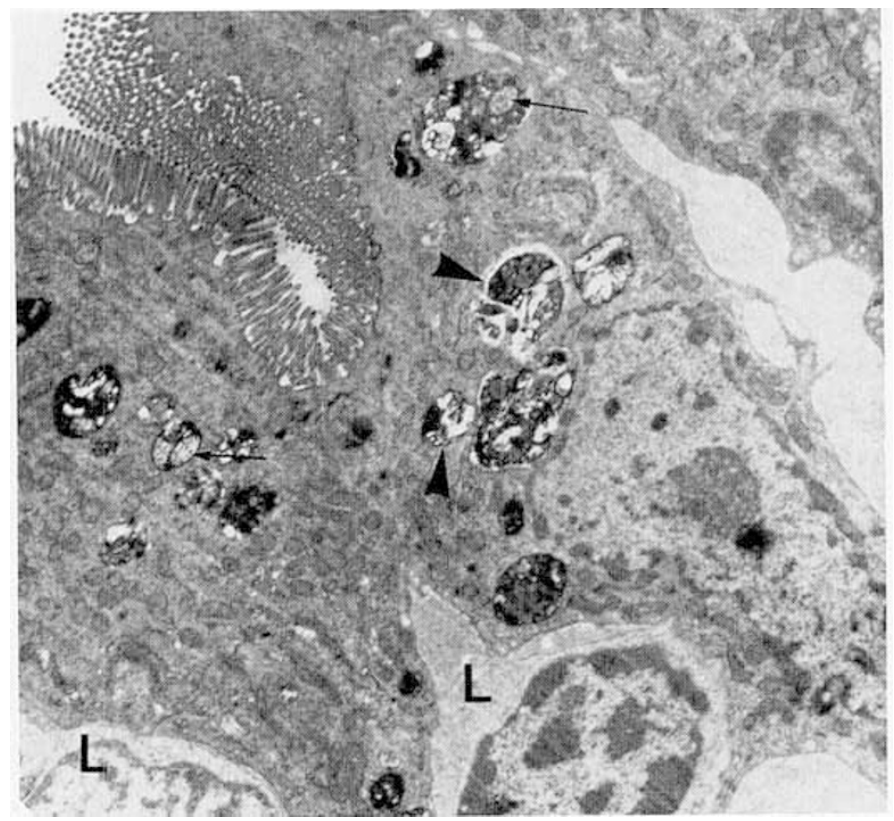

Fig. 5. Villous enterocytes with numerous pleomorphic inclusion bodies (arrowheads). Note structures resembling degenerating mitochondria (arrows) in the inclusion bodies and infiltrating lymphocytes $(L)$. Adult Coeliac Disease. Jejunum $\times 7300$.

In both $\mathrm{AE}$ and in coeliac disease these inclusion bodies appeared to contain remnants of goblet cells including large mucin masses. They were much larger and morphologically unlike the multivesicular bodies described by Braun et al. (3). They were only present when the patient's plasma zinc was low and signs of zinc deficiency were evident.

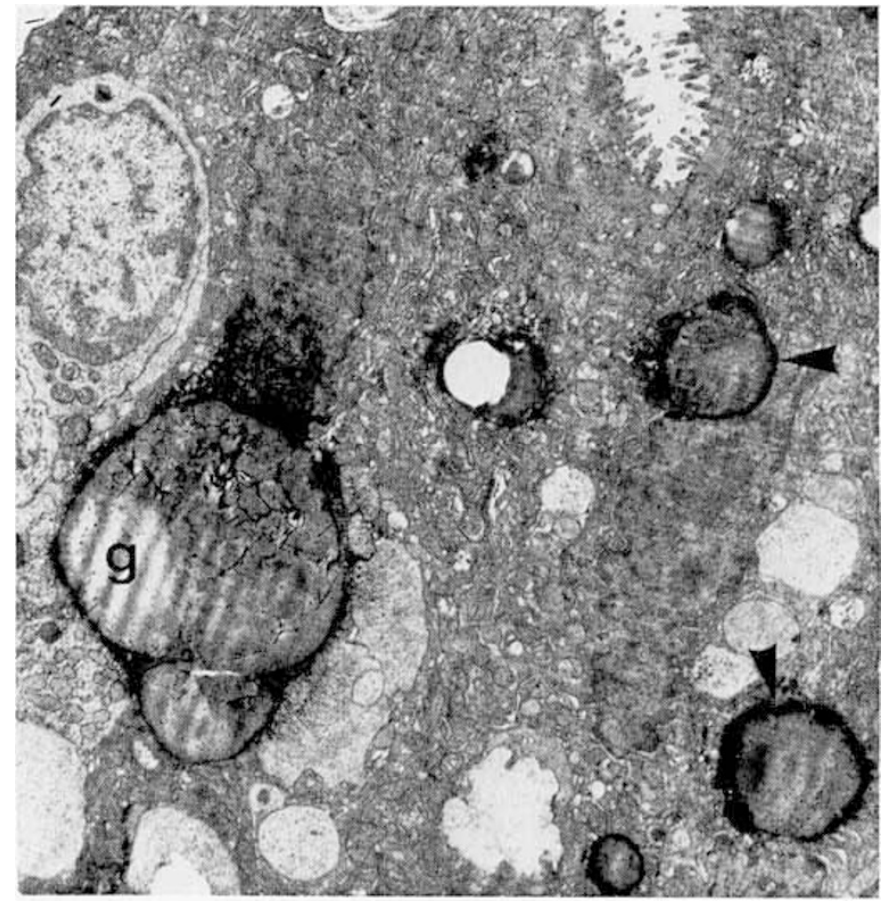

Fig. 6. Villous enterocytes with inclusion bodies (arrowheads) of similar composition to an adjacent degenerating goblet cell $(g)$. The inclusion bodies are very similar to the large floccular bodies seen in Figure 1. Adult Coeliac Disease. Jejunum $\times 5900$.

Zinc deficiency has been reported in coeliac disease (7), the other condition in which the abnormal inclusion bodies were found. There is no evidence at present that zinc deficiency alone causes goblet cell abnormalities although abnormal Paneth cells are found in $\mathrm{AE}$ (11) which can return to normal after zinc therapy (2).

Abnormal Paneth cells were found in these three patients with $\mathrm{AE}$ and it is possible that zinc is essential for normal secretory granule formation, stabilization and release in both Paneth and goblet cells. Abnormal pancreatic acinar cells have been reported in zinc deficient rats (10) so zinc may be necessary for normal secretion in all exocrine and endocrine cells.

It is suggested that some of the large abnormal lysosomal inclusion bodies found in both $\mathrm{AE}$ and in coeliac disease are derived from phagocytosis of damaged goblet cells by adjacent epithelial cells (8) and that the goblet cell abnormalities are due to zinc deficiency.

Patients with AE on therapy who have minimal structural abnormalities of the intestinal mucosa still have abnormal mucosal zinc uptake as shown by the tissue:medium concentrations, which have not been significantly improved by the return to normal appearance.

\section{REFERENCES AND NOTES}

1. Atherton, D. J., Miller, P. R., Aggett, P. J., and Harries, J. T.: A defect in zinc uptake by jejunal biopsies in acrodermatitis enteropathica. Clin. Sci., 56:505 (1979).

2. Bohane, T. D., Cutz, E., Hamilton, J. R., and Gall, D. G.: Acrodermatitis enteropathica, zinc and the Paneth cell. Gastroenterology 73: 587 (1977).

3. Braun, O. H., Heilmann, K., Pauli, W., Rossner, J. A., and Bergmann, K. E.: Acrodermatitis Enteropathica, Recent Findings, Europ. J. Pediatr. 121: 247 (1976).

4. Braun, O. H., Heilmann, K., Rossner, J. A., Pauli, W., and Bergmann, K. E.: Acrodermatitis enteropathica, zinc deficiency and ultrastructural findings. Europ. J. Pediatr. 125: 153 (1977).

5. Brunser, O., Castillo, C., and Araya, M.: Fine structure of the small intestinal mucosa in infantile marasmic malnutrition. Gastroenterology, 70: 495 (1976)

6. Dobbins, W. O.: An ultrastructural study of the intestinal mucosa in congenital B lipoprotein deficiency. Gastroenterology, 50: 195 (1966)

7. Elmes, M. E., Golden, M. L., and Love, A. H. G.: Unresponsive coeliac disease. 
Quart, J. Med., 45: 696 (1976).

8. Elmes, M. E., and Gwyn Jones, J.: Ultrastructural studies on Paneth cell apoptosis in zinc deficient rats. Cell Tissue Res., 205: 57 (1980).

9. Hahn, K. J., Krishkofski, D., Weber, E., and Morganstern, E.: Morphology of gastrointestinal effects of aspirin. Clin. Pharmacol. Ther., 17: 330 (1975).

10. Koo, S. 1., and Turk, D. E.: Effect of zinc deficiency on the ultrastructure of the pancreatic acinar cell and intestinal epithelium in the rat. J. Nutr., 107: 896 (1977).

11. Lombeck, I., Von Bassewitz, D. B.. Becker, K., Tinschmann, P., and Kastner, H.: Ultrastructural findings in acrodermatitis enteropathica. Pediatr. Res., 8: 82 (1974).

12. Mathan, M., Mathan, V. I., and Baker, S. J.: An electron microscopic study of jejunal mucosal morphology in control subjects and in patients with tropical sprue in Southern India. Gastroenterology, 58: 17 (1975).

13. Moynahan, E. J., Johnson, F. R., and McMinn, R. M. H.: Acrodermatitis Enteropathica, demonstration of possible enzyme defect, Proc. Roy. Soc. Med., 56: 300 (1963)

14. Shiner, M.: Jejunal surface epithelium in idiopathic steatorrhoea. Br. Med. Bull. 23: 223 (1967).

Copyright (C) 1983 International Pediatric Research Foundation, Inc. $0031-3998 / 83 / 1705-0354 \$ 02.00 / 0$
15. Thyberg, J., Graf. W., and Klingenstrom, P.: Intestinal fine structure in Crohn's disease. Virchows. Arch. (Pathol., Anat.), 391: 141 (1981).

16. Toner, P. G., Carr, K., and Wyburn, G. M.: The digestive system. An ultrastructural atlas and review. Butterworths, London, (1971).

17. This study was approved by the Standing Committee on Ethical Practice of the Hospital for Sick Children, Great Ormond Street, London, and informed consent was obtained from the parents of the children. Informed consent was obtained from either the patients or their legal guardians for diagnostic biopsy.

18. Dr. Gwyn Jones was supported by the Welsh Scheme for the Development of Health and Social Research. We thank Dr. P.M. Smith, Llandough Hospital, Penarth, for biopsies from adults and the physicians of the Department of Child Health, University Hospital of Wales for biopsies from children. Dr. P.J. Aggett wishes to acknowledge financial support from the Medical Research Council and to thank Mrs. V. Smith and Dr. Brian Lake of the Institute of Child Health for technical assistance.

19. Requests for reprints should be addressed to: Dr. Margaret E. Elmes, Department of Pathology, University of Wales, Heath Park, Cardiff, CF4 4XW.

20. Received for publication April 14, 1982.

21. Accepted for publication August 6, 1982.

Printed in U.S.A. 